\title{
Psychological experiences in South African society before the 2010 FIFA World Cup from the systems psychodynamic and positive psychology perspectives
}

\author{
Authors: \\ Pieter Koortzen ${ }^{1}$ \\ Rudolf M. Oosthuizen² \\ Affiliations: \\ ${ }^{1}$ Department of Industrial \\ Psychology and People \\ Management, University of \\ Johannesburg, South Africa \\ ${ }^{2}$ Department of Industrial \\ and Organisational \\ Psychology, University of \\ South Africa, South Africa \\ Correspondence to: \\ Pieter Koortzen \\ Email: \\ pieter_koortzen@yahoo.com \\ Postal address: \\ PO Box 392, UNISA 0003, \\ South Africa \\ Dates: \\ Received: 24 Feb. 2011 \\ Accepted: 20 Dec. 2011 \\ Published: 03 May 2012 \\ How to cite this article: \\ Koortzen, P., \& Oosthuizen, \\ R.M. (2012). Psychological \\ experiences in South African \\ society before the 2010 FIFA \\ World Cup from the systems \\ psychodynamic and positive \\ psychology perspectives. \\ SA Journal of Industrial \\ Psychology/SA Tydskrif vir \\ Bedryfsielkunde, 38(2), Art. \\ \#976, 13 pages. http:// \\ dx.doi.org/10.4102/sajip. \\ v38i2.976
}

Orientation: The researchers conducted a literature review to analyse the assumptions of systems psychodynamics, the Tavistock model of group relations, object relations theory and the most relevant constructs in the systems psychodynamic perspective. They then described the assumptions and most relevant constructs in the positive psychology perspective in order to analyse theoretically the psychological effect of large-scale sports events on a community or country. The objective of the empirical study was to investigate some of the unconscious emotions, fears, anxieties and conflicts (dynamics) that prevailed in South Africa before the 2010 Fédération Internationale de Football Association (FIFA) World Cup and some of the positive emotional experiences associated with it.

Research purpose: The objective of this study was to analyse and describe the psychological experiences of South Africans before the 2010 FIFA World Cup.

Research design, approach and method: The researchers conducted the study from the systems psychodynamic and positive psychology perspectives. The study comprised a qualitative, explorative and social phenomenological study. The researchers conducted interviews with a wide range of their colleagues and clients.

Main findings: The results seemed to indicate that South Africans had had a number of positive and negative experiences before the 2010 FIFA World Cup.

Practical/managerial implications: The researchers presented the findings as a number of systems psychodynamic and positive psychology themes.

Contribution/value-add: This study presents original research that contributes valuable new knowledge to the positive psychology and systems psychodynamic perspectives.

\section{Introduction}

\section{Key focus of the study}

The assumption is that South Africa will never be the same after hosting the 2010 FIFA World Cup because of the enormous psychological effect the event had on the host nation. Therefore, staging the 2010 FIFA World Cup offered a unique opportunity for South Africa (Doaldson, Cornelissen, Swart \& Bob, 2008). Hosting the event carries considerable prestige. In addition, the spin-offs of the tournament could advance the psychological health and quality of life in South Africa. Although South Africa's bid to stage the 2000 Olympic Games was unsuccessful, the country's earlier successful hosting of (and victory at) the 1995 Rugby World Cup prompted further sustained campaigns to host more mega-sports events like the 2010 FIFA World Cup (Labuschagne, 2008).

One should view the initiative and drive of the government and the organising bodies to stage mega-sports events in the context of South Africa's situation as a developing country (Labuschagne, 2008). The aim of staging international events was also to accrue benefits for key social, cultural and political development programmes. The most notable of these objectives was to use sport and recreation as a way of supporting the government's nation-building initiatives (Cornelissen \& Swart, 2006). The former president of South Africa, President Mandela, acknowledged that sport has a unifying effect on a country. He referred to the fact that 'sport speaks a language which politicians can't' (Mandela, 2008).

The effect of sport on the psyche of a nation is a theme in psychology, sociology and other disciplines. Research into this theme can create a wealth of knowledge that one can use to develop societies and nations. Therefore, it is surprising that few scholars have actually studied
(C) 2012. The Authors Licensee: AOSIS OpenJournals. This work is licensed under the Creative Commons Attribution License. 
the psychological potential of sport as a nation builder in a fragmented society (Labuschagne, 2008). Scholars, who study the history and dynamics of sport, have accepted that sport is inseparable from nationalism and can be a powerful tool in the hands of politicians (Chandler, 1999).

\section{Background to the study}

Politicians successfully used sport in South Africa as a nation builder to mend the cultural divisions in the country. The triumph of the 1995 Rugby World Cup remains firmly embedded in the minds of most South Africans. Most will also be able to recall how a divided and troubled country became, for the first time, truly united, albeit temporarily, as the 'Rainbow Nation'. The triumph of two major sports events, the 1995 Rugby World Cup and the 1996 Africa Cup of Nations, held in South Africa shortly after the first democratic election, had a huge effect on nation building in South Africa (Labuschagne, 2008).

One often defines sports events in terms of their potential positive effects instead of in neutral phenomenological terms. In this sense, conceptualising sports events, as planned occurrences of limited duration that have an extraordinary effect (Saayman, Saayman \& Du Plessis, 2005), or which increase the awareness and appeal of the host area as a future tourist destination (Ritchie, 1988), indicates how cause and effect become intertwined with the semantics of the phenomenon (Burnzett, 2008).

A reductionist perspective yields a broad-base multilevel analysis and may reveal the bigger picture (Chalip, 2006). Effects at different levels link inevitably to reflect similar manifestations, at the level of society, the community and/ or individual, to convey a collective understanding of the complex whole (Anderson, Rustad \& Solberg, 2004; Cunningham \& Beneforti, 2005). Therefore, one may interpret the feeling of a collective euphoria, at a macro or national level, as social cohesion and nation building. It appears as community integration at meso-level and as an increased feeling of self-worth and belonging at the micro or individual level (Burnett, 2008).

The economic effect converts into potential increased assets for economic survival, finding employment and access to resources (Burnett, 2007). The social effect converts into forging mutually beneficial relationships, networking and social integration. It includes the political and cultural dynamics and normative behaviour that relate indirectly to social deviance and criminal behaviour, with safety and security as the other side of these phenomena. Sport, recreation and physical activity, as an indicator field, focuses mainly on participation and other directly sports-related phenomena. Selectively integrating some of these elements means health and quality of life (Burnett, 2008; Cunningham \& Beneforti, 2005; Burnett \& Hollander, 2007). This type of quantification also links to potential positive and negative effects. Table 1 shows this.

\section{Research purpose}

Although the literature has focused some attention on the psychological effects of sport events on the psychological functioning of a society or nation, the researchers in this study believe that more in-depth research is required to understand this phenomenon fully. Therefore, the objective of this research was to investigate some of the unconscious conflicts and dynamics, anxieties, emotions and fears in South Africa before the 2010 FIFA World Cup. The researchers also investigated some of the positive emotional experiences

TABLE 1: Effect of sports as hallmark events.

\begin{tabular}{|c|c|c|}
\hline Effect & Positive & Negative \\
\hline Economic, tourism or commercial & $\begin{array}{l}\text { Increased expenditure } \\
\text { Employment opportunities } \\
\text { Education and training } \\
\text { Marketing the region as a tourism destination }\end{array}$ & $\begin{array}{l}\text { Price increases during the event } \\
\text { Real estate speculation } \\
\text { Short-term contract work } \\
\text { Limited access of the rural poor to employment } \\
\text { opportunities }\end{array}$ \\
\hline Infrastructure and physical resources & New improved infrastructure and local facilities & $\begin{array}{l}\text { Underused sport and associated facilities after the event } \\
\text { Limited access and redistribution of resources } \\
\text { Long-term management and maintenance }\end{array}$ \\
\hline Social, cultural and political effects & $\begin{array}{l}\text { International recognition of the region (resorts and } \\
\text { investment) } \\
\text { Propagating political values and ideology } \\
\text { Social integration and 'nation-building' } \\
\text { Local, community and national identity as well as pride } \\
\text { Revitalising traditions } \\
\text { Increased security at events }\end{array}$ & $\begin{array}{l}\text { Exclusion of minorities } \\
\text { Displacement of tenants } \\
\text { Divisions because of exclusions (race, gender and class) } \\
\text { Distorting nature and 'effect' of the event } \\
\text { Manipulating community and disrupting community life } \\
\text { Selective representation and intergroup hostility } \\
\text { Increased theft, traffic congestion, noise and prostitution }\end{array}$ \\
\hline Psychological and health or quality of life & $\begin{array}{l}\text { Local or national pride (liminality) } \\
\text { Awareness of outsiders' perceptions } \\
\text { Increase in the quality of life of higher socioeconomic } \\
\text { classes because of improved amenities } \\
\text { Access to health services and education }\end{array}$ & $\begin{array}{l}\text { Defensive attitudes about host region } \\
\text { Fan delinquency, crowding and noise } \\
\text { Loss of control over local environment } \\
\text { Misunderstandings and intragroup loyalty leading to host } \\
\text { or visitor hostility } \\
\text { Reduced quality of life for low-income groups because of } \\
\text { inflated prices of goods and services } \\
\text { Disrupted local lifestyles }\end{array}$ \\
\hline Sport and recreation & $\begin{array}{l}\text { Programmes, services and facilities (see infrastructure) } \\
\text { Education and training } \\
\text { Increased volunteerism and community group activity } \\
\text { (intercultural interaction) }\end{array}$ & $\begin{array}{l}\text { Temporary access and regional focus } \\
\text { Quality programmes and structures to sustain them } \\
\text { Access to needs based accredited training to increase } \\
\text { employability } \\
\text { Access, resources and structures for sustained delivery } \\
\text { Bias towards elite performance }\end{array}$ \\
\hline
\end{tabular}


associated with the 2010 FIFA World Cup. As a point of departure, they analysed the theoretical psychological effect of the event from the systems psychodynamic and positive psychology perspectives. They did so in order to answer the two research questions that follow:

- What were some of the conflicts, dynamics, anxieties, unconscious emotions and fears in South African society before the 2010 FIFA World Cup?

- What were some of the positive emotional experiences associated with the 2010 FIFA World Cup in South African society?

\section{Systems psychodynamics}

Systems psychodynamics is an interdisciplinary field that integrates the practice of psychoanalysis, the theories and methods of group relations and open systems perspectives. It is a term that refers to the collective psychological behaviour within and between groups, organisations or systems. Therefore, it provides a way of thinking about the energising, or motivating, forces that result from the interconnection between various groups of a social system (Neumann, 1999). It also deals with many of the taboos that lie deep below the surface in a group, organisation or community (Czander, 1997). In this study, 'taboo' highlights how often groups, organisations or communities ignore, discount or control emotions and fears.

There are still deep divisions in South African society because of the political and social history of the country. One can only wonder about the motivational forces that were operating in different groups before the 2010 FIFA World Cup and what type of relationships and relatedness (interconnectedness) existed between the different groups. In order to analyse these, the researchers used the psychodynamic theories that follow in this research.

\section{Psychodynamic theory}

In this article, the researchers describe systems psychodynamic theory with reference to the object relations theory, the Tavistock group relations theory and the basic assumptions of this model. As part of the systems psychodynamic perspective, they also address systems theory.

\section{Klein's object relations theory}

This is an offshoot of psychoanalytic theory. It emphasises interpersonal relations, primarily in the family but especially between mother and child (Klein, 1985; 1987). The word 'object' actually means a person, especially the person who is the object or target of another's feelings or intentions. The term 'relations' refers to interpersonal relations and suggests the residues of past relationships that affect a person in the present.

Object relations theorists are interested in inner images of the self and others and how they appear in interpersonal situations. In this study, the researchers thought it appropriate to consider object relations theory when they tried to analyse the psychological effect of the 2010 FIFA World Cup visitors on South African society and the types of relationships South Africans would form with these visitors. The researchers studied the concept of anxiety, which is central to psychodynamic and object relations theories, in order to analyse the possible psychological effects of the 2010 FIFA World Cup on South African society (Daniel, 2010; Likierman, 2001). In her object relations theory (Arronga, 1975; Klein, 1985; McCarthy, 1985), Melanie Klein explained this concept by identifying three types of anxieties:

- primitive anxieties arise from work and personal anxieties, are always present and fall into persecutory and depressive types

- persecutory anxiety is associated with annihilation (Segal, 1992), leads to paranoia and splitting (paranoid-schizoid position)

- depressive anxiety is associated with the fear that one's destructive impulses will destroy the dependent and love object (Czander, 1993; Jaques, 1955; Miller 1993).

People use different defence mechanisms to cope with anxiety. It leads one to raise the question of which defence mechanisms they use and how groups, systems or societies with anxiety react. The reactions to anxiety may appear in the defence mechanisms of denial, projection, rationalisation and intellectualisation. An alternative view suggests that the South African community could also use the event for reparation and reconciliation. The Tavistock model of group relations (Czander, 1993; Miller 1993) is a theoretical model that one can use to analyse the South African situation and the anxiety-provoking experience of the 2010 FIFA World Cup further.

\section{Tavistock group relations theory}

According to this model, as Banet and Hayden (1977) and Bion (1974) describe it, an aggregate cluster of persons becomes a group when interaction between members occurs, when an awareness of a common relationship develops and when a common group task emerges. According to these authors, a number of forces can operate to produce a group. These include an external threat, a collective threat and collective regressive behaviour or attempts to satisfy needs for security, safety, dependency and affection. They could describe the South African situation in which individuals and small groups identify a common external, collective threat (here, the 2010 FIFA World Cup visitors). In an attempt to satisfy their security, safety and dependency needs, they suddenly have to form a united front against the foreign onslaught. They also need to complete a common task in order to host a successful event. Therefore, one can argue that the 2010 FIFA World Cup could have played a unifying role and allowed South Africans to unite in a unique way if people could cope effectively with the underlying anxiety of the situation.

Bion (1974) also believes that, when the aggregate becomes a group, the group behaves as a system - an entity that, in some respects, is greater than the sum of its parts - and the primary task of the group is survival. Although the group frequently disguises this, Bion believes that group survival 
becomes the latent motivating force for all group members. A phenomenon called 'group-as-a-whole' starts to emerge. It requires members to see and focus on the collective interactions that group members generate. In Gestalt terms, the group is focal and individuals are in the background. It is possible to summarise the group-as-a-whole approach.

The primary task of any group revolves around what it must do to survive. In this research, this would imply overcoming some of the divisions of the past and working together as a unit to survive the 2010 FIFA World Cup. The group also has a life of its own only because of the fantasies and projections of its members. Furthermore, the group uses its members to achieve its primary task and the behaviour of group members at any moment is an expression of their own needs, history and the behavioural patterns of the group. This is evident in the South African context. Politicians from different parties, as well as men and women from sports other than soccer, acted as ambassadors of the 2010 FIFA World Cup. Theorists also believe that, whatever the group is doing or talking about, it is always talking about itself (Banet \& Hayden, 1977; Bion, 1974).

In the South African context, this manifested in a great deal of talk about the extent to which South Africa, as a collective, was prepared for this world event, how the visitors would experience South African culture and hospitality and what they would think of South Africans after the event. Finally, Bion (1974) believes that, by reflecting on themselves and attempting to understand the process of the group, group members are able to make previously unavailable choices about their identities and functions in a group setting. An example of this is the recent decision of the Blue Bulls rugby team to play an international rugby match on a soccer field in Orlando, Soweto - one of the largest traditionally 'Black' cities in South Africa.

\section{Basic assumptions}

At the basic assumption level of functioning, the group behaves as if certain assumptions are true and valid and as if certain behaviours are vital to the group's survival. Here, 'basic' refers to the survival motive of the group whilst 'assumption' emphasises that the basis of the survival motive is not fact or reality but the collective projections of group members (Lawrence, 1999). Bion (1974) identifies three distinct types of basic assumptions: dependency, fight or flight and pairing. Turquet (1974) added a fourth assumption, that of one-ness and me-ness.

Dependency: The assumption here is that group members, like children, are unconsciously dependent on imaginative parental figures or systems. Because the group does not always meet these needs for parenting, acceptance and love, group members experience frustration, helplessness, powerlessness and disempowerment. Typical questions here might be:

- Why are the leaders not giving us more attention and helping us?

- What do they want me to do?
These questions, according to Cilliers and Koortzen (2000), are projections of the members' own anxiety and insecurity and show work and emotional immaturity. One can also see this defence against anxiety as a manipulation of authority out of its role, say from leader to parental figure, according to the fantasy that then 'we will be safe and cared for'.

In the South African context, members of the public seemed to depend greatly on the leaders and the organisers of the 2010 FIFA World Cup. The dependency manifested in requests for jobs and entrepreneurial opportunities during the 2010 FIFA World Cup. There was also the fear that the promises of jobs and increased income would not materialise during the event and that leaders had forgotten the basic reasons for hosting it.

Fight or flight: The assumption here is that the here-andnow of group life is fraught with anxiety. In trying to escape from this anxiety, group members unconsciously use fight or flight as their defence mechanisms. Fight reactions appear as aggression against the self, group members (envy, jealousy, competition, elimination, boycotting, sibling rivalry, fighting for position in the group and privileged relationships with authority figures) or against authority itself. Flight reactions appear as avoidance of others, withdrawal or physical flight. Psychological flight reactions include defence mechanisms like avoiding threatening situations or emotions in the hereand-now, rationalising and intellectualising (Koortzen \& Cilliers, 2002).

South Africans seemed to show both types of reactions. Firstly, one observed fight reactions in the frantic attempt to obtain tickets for the 2010 FIFA World Cup. The competition during the initial phase of ticket sales was clear and this escalated to some violence closer to the event. The flight reactions manifested in some South Africans' attempts to obtain airline tickets to leave the country during the 2010 FIFA World Cup. Speculation about overcrowding, traffic problems, crime and price hikes seemed to fuel these anxieties and flight reactions.

Pairing: The assumption here is that, in order to cope with anxiety, alienation and loneliness, the individual or group tries to pair up with people or subgroups they see as powerful. The unconscious need, according to Bion (1961) and Lawrence (1999), is to feel secure and to create. The unconscious fantasy is that creation will occur in pairs. Pairing also implies that the group is splitting up. This happens when members experience anxiety because of differences. The individual or team tries to split up the whole and build a smaller system to which they can belong and in which they feel secure. This pairing also manifests in ganging up against the perceived aggressor or authority figure.

Intragroup and intergroup conflict can result from pairings. This behaviour can also split the team emotionally (Koortzen \& Cilliers, 2002). These pairings were obvious in the initial phases of planning for the 2010 FIFA World Cup. Some White South Africans, who are traditionally rugby and cricket supporters, paired and expressed negative thoughts 
and feelings about the event. On the other hand, Black South Africans, who are soccer supporters, supported the event fully. In the last few months before the event, this situation seemed to change significantly. Many White South Africans were just as enthusiastic about the event and formed strong relations with Black South Africans against the perceived enemy. Turquet (1974) added two assumptions to Bion's original ones. These were 'one-ness' and 'me-ness'.

One-ness: According to Turquet (1974), the assumption here is that group members try to join a powerful union with an omnipotent force. They surrender the self to passive participation and experience existence, well-being and wholeness. It seems that the group members lose themselves in oceanic feelings of unity. One can see this as a desire for salvationist inclusion in a group that is striving for cohesion and synergy. Group members believe that this strong united force will solve problems. In the South African context, this first appeared in society's attempts to reconcile after the 1994 election (Koortzen \& Cilliers, 2002). This seemed to be happening again in the final preparation phase for the 2010 FIFA World Cup.

Me-ness is the opposite of one-ness. This assumption refers to the risk of living in a contemporary and turbulent society (Turquet, 1974). Group members feel increasingly forced into their inner reality in order to exclude and deny the reality of the outer environment that they see as disturbing. The inner world becomes the comfortable place and the outer the one they should avoid.

The group works on the tacit, unconscious assumption that the group should be a non-group. Members can only relate to the people who are present because they share the idea that the group is an undifferentiated mass. Therefore, they act as though the team does not exist. If it did, it would be the source of persecuting experiences. The idea of a group is contaminating, taboo and impure. The members act as though the group has no reality and that the only reality is that of the individual. The individual's reality exists in a culture of selfishness in which the individual is only aware of his or her personal boundaries that he or she must protect. This leads to instrumental transactions with no room for affect (that people experience as dangerous because they do not know where their feelings might lead). This resistance of people to becoming part of the group can affect the society's performance negatively. For example, in the predominantly Black collectivist South African culture, White citizens seem to feel threatened about losing their individuality. Therefore, they show this kind of resistance (Koortzen \& Cilliers, 2002).

\section{Systems theory}

Bertalanffy (1968), a biologist, used systems theory as the basis for 'general systems theory', a multidisciplinary field of study. One can find some influences from the contingency approach in this theory. Systems theory is a transdisciplinary study of the abstract organisation of phenomena, irrespective of its substance, type or spatial or temporal scale of existence.
It investigates the principles that are common to all complex entities and the (usually mathematical) models that one can use to describe them.

A system consists of four elements. The first is objects - the parts, elements or variables in the system. These may be physical, abstract, or both, depending on the nature of the system. The second element of a system is its attributes the qualities or properties of the system and its objects. The third element of a system refers to the internal relationships between its objects, whilst the fourth element refers to the fact that a system exists in an environment. A system is a set of elements that affect one another in an environment and form a larger pattern that is different from any of its parts. One can see this interaction as the ongoing stages of input, throughput (processing) and output, which demonstrate the concept of openness and its opposite (closedness). A closed system does not interact with its environment and may eventually become isolated or even vanish. An open system receives information that it uses to interact dynamically with its environment. This openness increases its likelihood of surviving and prospering.

In this research, it was important to understand the closedness or openness of South African society to accepting large numbers of foreign visitors into the country and its openness to share responsibilities, experiences and anxieties with fellow South Africans. South Africa was one of the most closed societies in the world before 1994. This left the country isolated and South Africans with little experience of interacting with large groups of foreigners. This leads to the question of the extent to which South Africans would open themselves to the new experiences the 2010 FIFA World Cup offered.

\section{Positive psychology}

According to Seligman and Csikszentmihalyi (2000), the field of positive psychology, at the subjective level, is about valued subjective experience: well-being and satisfaction as they relate to experiences, hope and optimism for the future, as well as flow and happiness in the present. These authors believe that, at the level of the individual, it is about positive personal traits. They include the capacity for love and vocation, courage, interpersonal skill, aesthetic sensibility, perseverance, forgiveness, originality, future-mindedness, talent and wisdom. At the level of groups, it is about the civic virtues and the institutions that move people towards better citizenship: responsibility, nurturance, altruism, civility, moderation, tolerance and work ethics. It has three areas of study.

Compton (2005) and Seligman (2002) describe the first field as the study of a 'pleasant life' or a life of enjoyment. This involves the extent to which people experience, forecast and savour positive feelings and emotions (like relationships, hobbies, interests, entertainment and sport). The second field is that of a 'good life', or a life of engagement. According to Compton (2005) and Seligman (2002), it involves the beneficial effects 
of immersion, absorption and flow that people feel when they are fully engaged in their primary activities (person, job or match). The third field is the 'meaningful life', or a life of affiliation. This is the extent to which people derive a sense of well-being, belonging, meaning and purpose from being part of something (like nature, social groups, organisations, movements, traditions and belief systems).

In a country riddled with crime and violence, most South Africans seemed to welcome the opportunity to experience something of the pleasant life or a life of enjoyment. There seemed to be a definite anticipation and forecast of positive feelings and emotions before the 2010 FIFA World Cup. One can see this from the positive energy and the relationships that existed between South Africans from different groups and the hope that the event would play a unifying role in the country. In certain sense, hosting the 2010 FIFA World Cup had also became a collective task in which many South Africans could participate.

This form of engagement seemed to bring meaning to the lives of many South Africans and could represent a good life or a life of engagement (Lowman, 2002). Many South Africans seemed to be involved in preparing the country for the 2010 FIFA World Cup and one could see the beneficial effects of immersion, absorption and flow in South African society. An example of this was the enthusiasm with which many South African mobilised their employees to take part in the event. 'Soccer Fridays' and learning about the cultures and customs of the different countries that participated in the event were common in the workplace.

However, the most significant psychological effect of the 2010 FIFA World Cup may have come from the affiliation, positive sense of well-being, belonging, meaning and purpose of being part of something that many South African were already reporting. People were flying the national flag with a great deal of pride. Collective customs and soccer behaviours crystallised in South African society. Some of these soccer behaviours also moved to other sports types in the country. Blowing the vuvuzela, a trumpet-like instrument, also became common at rugby games.

'Character strengths and virtues (CSV): a handbook of traits' (Peterson \& Seligman, 2004) describes a number of virtues and strengths. It raises the question of the extent to which the 2010 FIFA World Cup would allow South Africans to explore and develop some of these traits and their resulting character strengths.

The first trait of 'wisdom and knowledge', which includes creativity, curiosity, open-mindedness, love of learning, perspective and innovation, could be particularly valuable traits in South African society. South Africans, who were willing to expose themselves to the great diversity of visitors who attended the 2010 FIFA World Cup, may develop new perspectives about human behaviour and intergroup relations. Exposure to these visitors and developing relationships, even for a short period, may result in new knowledge and wisdom that South Africans can use with great success. Being 'courageous', which includes bravery, persistence, integrity and vitality, will assist many South Africans to work through some of the perceptions and stereotypes they associate with different groups in South Africa. This will involve, for example, being brave enough to attend soccer matches at different venues and in geographical areas outside their comfort zones.

\section{Potential value-add of the study}

The 2010 FIFA World Cup will allow South Africans to develop 'humanity' (which involves love, kindness and social intelligence) in a country known for its inhumane practices and behaviours. It will be a significant move towards promoting a more integrated and just society. Although the effect of the 2010 FIFA World Cup and the development of these traits may only emerge long after the event, the climate in the country and the attitude of kindness one month before the event was noticeable amongst many South Africans. In a traditionally unjust society, developing traits, like 'justice' and citizenship, are very important in a healthy society.

There is also the hope that the 2010 FIFA World Cup will allow South Africans to develop 'temperance', forgiveness and mercy, humility, prudence and self-control. Forgiveness and mercy are prerequisites for healthy relationships. Although South African society has made significant progress here, there are still great divisions between the different population groups. Finally, many South Africans have expressed the hope that this event will allow South Africa to 'transcend' the past and develop an appreciation for the beauty of the country and its people. Gratitude, hope, humour and a new spirit will mediate the negativity of many South Africans.

\section{What will follow}

The section that follows outlines the research design, the research approach, the research strategy and the research method. The findings of the qualitative study, a discussion of the findings and some recommendations for future research follow.

\section{Research design Research approach}

The research approach comprised a qualitative, explorative and social phenomenological study (Mouton, 1996) using interviews (Kerlinger \& Lee, 2000; Camic, Rhodes \& Yardley, 2003). Phenomenological research aims to describe the subjective reality of an event, as the study population perceives it. Therefore, it involves studying a specific phenomenon. In this study, it involved the subjective experiences of participants about the 2010 FIFA World Cup in South Africa before it happened. The researchers used systems psychodynamic and positive psychology perspectives to interpret the themes that emerged. 


\section{Research strategy}

Qualitative researchers often use the case study method, where they use a single or several cases to develop or test theory. This research involved interviews with 24 participants. The researchers made a number of philosophical and practical decisions whilst developing the research strategy. Firstly, the researchers decided that the participants were participants and not 'subjects' and that they were active participants in the research. It meant that they 'informed' the researchers about their perceptions and feelings about the effects of the 2010 FIFA World Cup in South Africa (Doaldson, Cornelissen, Swart \& Bob, 2008). The researchers tried to understand the participants' perceptions and feelings. It meant learning as much as possible about the participants' perceptions and feelings during the interviews.

Secondly, the researchers decided that participants must have first-hand experience of the research topic and be able to talk about it. Therefore, the researchers decided to ask for formal interviews with participants who spontaneously spoke about the 2010 FIFA World Cup in informal discussions. This gave an indication of their psychological 'involvement' in the event and their willingness to discuss it (Labuschagne, 2008).

Thirdly, the researchers decided to continue the interviews until they had interviewed men and women, participants from different age groups (young adult, middle-aged and older adults) and representatives of all the population groups (Black, White, Indian and Coloured).

The eight participants in the young adult category consisted of four men between the ages of 20 and 27 and four women aged 23-30. The women and men participants represented the four race groups equally. In addition to representing the different race groups, these participants represented young adults in South African society and provided the researchers with some understanding of the perceptions of this group. They all had jobs and were clients of the researchers at the time of the research. This also suggests that the researchers had working relationships with these participants and facilitated a level of openness in the interviews. Only two of these participants were married.

The eight participants in the middle-aged category consisted of four men between the ages of 40 and 43 and four women aged 40-46. The women and men represented the four race groups equally and all the participants were married and had children. They represented the middle-aged members of society and the researchers expected different perceptions from them than from the first group. Only three members of this group said they were soccer supporters. The members of this group worked as middle or senior line and human resources managers whilst two were in consulting positions. Half of this group of participants were soccer supporters whilst the other half indicated that they had a fair understanding of the game. Therefore, they represented both supporters and non-supporters.
The eight participants in the older category consisted of four men between the ages of 51 and 70 and four women aged $52-65$. The women and men represented the four race groups equally and all the participants held senior management or consulting positions in different South African organisations. Six of the eight participants in this group considered themselves as soccer supporters whilst two described themselves as non-supporters.

\section{Research method}

The researchers describe the research method in terms of the research setting, the way they obtained entry to the research setting and how they established the researchers' roles.

\section{Research setting}

The researchers conducted the study using participants who worked in different South African organisations where the researchers were consulting at the time. As part of their consulting services, the researchers interact with many different members of South African society. They asked these clients and colleagues to take part in the research. After the researchers finished their normal consulting processes, they approached some of their clients and colleagues to take part in the research by asking them to take part in formal interviews. However, the researchers conducted the interviews outside of the clients' work places in order to emphasise that the research had no connection to the normal consulting and working processes or the relationships that the researchers had with the participants.

\section{Entrée and establishing researcher roles}

The researchers approached clients and colleagues who talked spontaneously about the event. They used the participants' interest in the topic as a point of entry to the research. These clients and colleagues were orientated towards the goals of the research and asked to take part as research participants. The researchers explained that their motivation for approaching these particular clients and colleagues was the informal discussions in which they had participated. This showed their interest in the topic and their psychological 'involvement' in the event. The researchers negotiated the boundary conditions for the interviews outside the context of their primary relationships with the participants. It is important to note that the researchers conducted the empirical study six months before the 2010 FIFA World Cup and that some of the dynamics may have changed in the interim (one month before the event).

\section{Sampling}

The researchers conducted the research amongst South African participants who worked in a number of South African organisations where the researchers were consulting at the time. The researchers had a clear idea of the type of participant they wanted to include in the research and they wanted to include participants of different race, gender and age groups. This resulted in a specific strategy. The researchers' had access to many South African employees 
in different organisations. Their professional working relationships with the participants led to a convenience sample (Gravetter \& Forzano, 2012). The people the researchers eventually included in the sample were either their clients or colleagues. They interviewed 24 participants.

\section{Recording of data}

The researchers first orientated the participants to the goals of the research during the 30-minute formal interviews. They then explained the confidentiality of the study and that they would record the data during the interview by taking notes. During the interviews, the researchers asked participants to describe their hopes and fears for the 2010 FIFA World Cup in South Africa. They explored the initial responses of the participants further in the interviews and recorded their perceptions and feelings in writing. The interviews focused on their positive experiences and anxieties. The interview question was 'what are your hopes and fears with regard to the 2010 FIFA World Cup in South Africa?' The followup questions provided a more in-depth understanding of the perceptions and feelings the participants expressed. The researchers took field notes about the behaviour of the participants after the interviews. They stored these written documents in a secure place for later analysis (Gravetter \& Forzano, 2012).

\section{Data analyses}

The researchers used the social phenomenological approach (Higgs \& Smith, 2003). This means that social power or status does not intimidate researchers whilst they remain concerned about relevant values and ethics. It also requires researchers to ask 'what is actually happening?' whilst exploring, 'looking again' and then reflecting in ruthless honesty. Higgs and Smith (2003) describe the procedure as an attempt to penetrate illusions in order to get to the realities that underlie them. The processing procedure firstly involved reading through all the responses a number of times to become familiar with the content. Secondly, the researchers read the responses again using Schafer's (2003) systems psychodynamic interpretive stance. The third step involved extracting examples of systems psychodynamic conflicts and anxieties as well as positive psychology themes from the data (Schafer, 2003). The researchers then clustered the different examples (Clarkson \& Nuttall, 2000). This revealed certain prominent themes (Braun \& Clarke, 2006). Finally, the researchers extracted common themes using phenomenological analysis (Higgs \& Smith, 2003; Marton, 1994).

\section{Strategies employed to ensure quality data}

Here, as in any social research, the researchers needed to ensure reliability and validity. There are two main criteria for this: trustworthiness and authenticity (Babbie \& Mouton, 2008; Bryman \& Bell, 2007).

Trustworthiness: In an attempt to increase the trustworthiness of the research, the researchers looked at credibility, transferability and dependability. When the data contain information from interviews with different participants, one may question the credibility because there are different accounts of social situations. Therefore, credibility means ensuring that one carries out the research using the principles of good practice (Babbie \& Mouton, 2008; Bryman \& Bell, 2007). The results and research findings should also confirm that the researchers correctly understood the social situation. In this research, these were the participants' perceptions of the future FIFA World Cup and the psychological effect of it. The researchers ensured respondent validation by providing the results and research findings to participants to obtain their comments as to whether they were accurate descriptions of the situation.

With regard to transferability, qualitative research usually focuses on a small group of people with similar characteristics. This implies depth rather than breadth of data. The researchers tried to understand the uniqueness and significance of certain aspects of the 2010 FIFA World Cup and to produce detailed or thick descriptions that present a rich account of the particular situation.

The researchers achieved dependability by involving a number of auditors who conducted the assessment and justified the theoretical inferences. In this research, the researchers achieved this by keeping detailed information that was accessible during all the research phases. They also involving peers as auditors during the course of the research and at the end to determine the extent to which they had followed the proper procedures. They presented the findings to these peers on two separate occasions and included their feedback in the results. Finally, the researchers took great care about confirmability and attempted to act in good faith by not allowing their personal values to sway the research findings in any way. Apart from reflecting on each other in this regard, they asked probing and challenging questions of each other during the research process.

Authenticity: The researchers also attended to the authenticity of the research. This refers to issues of the wider political effect of the research and includes a number of elements that Bryman and Bell (2007) recommend. The researchers included participants from different gender, race and age groups to ensure fairness in how they obtained the different opinions. They achieved ontological and educational authenticity by assisting participants to achieve a better understanding of their social situations and developing an appreciation of the perspectives of others about the 2010 FIFA World Cup. They did this by sharing the perspectives of others during the formal feedback sessions with the participants and answering their questions in an open and honest way during these feedback sessions.

\section{Reporting}

The researchers presented the themes they identified from the positive psychological perspective. Then they presented the themes that emerged from the systems psychodynamic 
perspective. These themes are the unique and detailed themes that they identified in this qualitative research.

\section{Findings}

The researchers identified five themes from the positive psychology perspective. The first was the hope the participants expressed that 2010 FIFA World Cup would improve the image of the country and clarify its role internationally. They expressed the hope that the event would provide the platform for South Africa to highlight the meaningful contribution the country could make if all South Africans stand together. The event would also allow visitors to develop a different and more positive perspective of South Africa and its role on the African continent as well as internationally.

It was an opportunity to show the world what an advanced country South Africa was at an economic, technological and infrastructure level, that South Africans have wisdom as well as knowledge and can be innovative. This wisdom and knowledge could also extend to human relationships. Experience has provided valuable insights into diversity and developing more effective race relations. This beacon of hope could also inspire other nations with similar racial problems and conflicts. They also expressed the hope that promoting the country in this way would increase tourism and economic growth. 'We hope that our visitors have a very positive experience in the country and will want to come back.'

Finally, it is worth mentioning that the participants expressed the hope that organising and presenting the event would expose many South Africans to people of other nationalities. This should assist developing knowledge about different cultures and values as well as the wisdom to treat others with respect.

The second theme that emerged from the data was that there was evidence of spiritual development, national pride and the development of social intelligence. According to the respondents, the event provided an opportunity to escape the negativity, crime and violence of the country, the mundane nature of everyday life and to celebrate the potential and spirit of South Africa. Pride was central to this theme and the participants expressed the hope that the event could be the dawn of a new era and spirit in South Africa and that South Africans could again be proud of their country and its people. The participants also saw it an opportunity for Black South Africans to claim back their pride and spirituality and show unity with their White counterparts (the theme of social intelligence). One should also not underestimate the prestige and competitive spirit associated with hosting a mega sports event.

The third theme that emerged from this research was the hope of a life of enjoyment. The participants expressed the hope that all South Africans would take part in the joy of this event. 'This is going to be a lot of fun! We deserve it!' This was undoubtedly a momentous experience for many South
Africans. The intense joy that many of them experienced in the build-up to the event was visible throughout the country. The positive effect of this event was also visible in the youth of the country. The opportunity to interact with sports role models could inspire many young South Africans.

The fourth theme that emerged from the study was the hope that the event would improve nation building, reconciliation and affiliation. The participants expressed this in the hope that the event would facilitate the identity integration, forgiveness, reconciliation and reparation that the country so desperately needs. This reconciliation and humanity theme emerged in the responses of most of the participants, who expressed the hope that the 2010 FIFA World Cup would also help to form identities, similar to that which the 1995 Rugby World Cup did, and help to develop more collective cultural values. This also extended simultaneously to building relationships with many nations and repairing others. At the micro level, it included developing relationships across race and gender boundaries and allowing opportunities to affiliate meaningfully. In essence, it refers to normalising society and a developing positive sense of well-being and belonging.

The fifth theme that emerged was that of economic growth. It pointed to a life of engagement. The participants expressed the hope that most South African would profit from this event through job creation and business opportunities, which would allow many more South Africans to become involved in meaningful activities. With unemployment in the first quarter of 2010 at $25.2 \%$, it is clear that South Africa desperately needs economic growth and development. Many of the participants felt that the high rate of unemployment contributed to the poverty, crime and violence in the country and that creating jobs was crucially important for South Africa. Some participants felt that many South Africans have not seen a difference in their lives since the first democratic elections in 1994 and have not really experienced the benefits of this new democracy. They are not fully engaged in primary activities and are not able to experience a meaningful life. Therefore, they expressed the hope that the event would facilitate economic growth and international competitiveness. These include creating jobs and developing critical skills in the workforce.

The researchers also identified a number of clear themes from the systems psychodynamic perspective. The first was that of persecutory anxiety. This resulted in pairing and splitting. Some of the participants seemed to pair with their countrymen and women against the visitors. They expressed the anxiety and threat of the 'invading' visitors in expressions like 'soccer hooligans' and 'don't provide accommodation for them because they will break your house down'. The splits between the participants also suggested that there were pairings and splits within the larger South African society. There seemed to be a split between those participants who were fully engaged in the 2010 FIFA World Cup and those who were uninvolved or may even have felt excluded. Participants defended possible feelings of guilt because they 
were not involved and because they feared exclusion by denying them. This was clear from statements like 'it does not impact me' and 'I am not touched by the event'. Splitting was also clear between soccer lovers and the non-soccer lovers. The latter defended their behaviour with statements like 'they will mob you at the venues', where 'they' referred to both visiting and local soccer lovers.

In a country where many older Black South Africans remain extremely aware of the past and need opportunities to reclaim their pride and honour, it seemed that there was also a split between older and younger Black South Africans. Older Black South Africans seemed to see the 2010 FIFA World Cup as an opportunity to redeem South Africa on the world stage and develop international status. However, the younger generation seemed more enthused by the opportunity to see a few international music stars in action during the opening and closing ceremonies: 'I am not interested in the soccer. I just want to see Beyonce and Jayzee at the closing ceremony.'

There also seemed to be a split between supporters of Bafana Bafana (the local name of the South African national soccer team) and sports sceptics. Whilst the supporters believed that the 2010 FIFA World Cup would provide an opportunity to build a sports legacy and make South Africans proud, the sceptics seemed to experience anxiety about the national team's ability to perform well or actually win the tournament. Statements like 'they (Bafana Bafana) don't actually deserve to be in the event' and 'we don't have a chance against countries like Germany' reflected this.

The researchers also identified pairing and splitting between those who believed in the potential of the event and the sceptics. Whilst the believers celebrated the potential of the event to create national pride and spirit, the sceptics reported anxiety about congestion, overcrowding, inflation, tickets prices, crime, prostitution and others. They also seemed to be anxious about security during the 2010 FIFA World Cup: 'will there be enough security during the event?' and 'will visitors be victims of crime during the event?' This anxiety included concerns about the image that the country would promote in the opening ceremony: 'will it be good enough and represent the country properly?' This is a typical example of the paranoid schizoid position.

The second theme was that of dependency and depressive anxiety. This was noticeable in the participants who expressed their dependency on, and anger towards, government and the organisers of the event. One the one hand, some participants believed that these two groups were responsible for presenting a successful event as well as creating economic prosperity and job opportunities for the millions of South Africans who were still poor. On the other hand, there was a fear that the country would not make a profit and that many South Africans would face economic disappointment after the event: 'will all South Africans profit from this venture?' and 'will small businesses and the small business owner also get a piece of the pie?' The participants expressed their feelings of anger and resentment about the government and the organisers directly. This resulted in a depressive position.

Linked to this was the third theme, in which participants expressed a lack of leadership. Compared to the 1995 Rugby World Cup, in which President Mandela played a reconciliatory, transformational and spiritual leadership role, there was no visible leadership for the 2010 FIFA World Cup. Although the head of the organising committee, Danny Jordaan, was fulfilling this role to some extent, the political leaders had not taken up the role effectively. Whereas the rugby and cricket world cups were steeped in symbolic importance, there was the fear that the significance of this might become diluted if the economic goals were not achieved.

The researchers identified a fourth theme, of fight and giving up, in the responses of some participants. Fighting and competition for tickets, as well as feelings of discrimination, were present early in the bidding process. Some participants felt that the electronic bidding process for tickets was unfair and had resulted in unnecessary envy, jealousy and paranoia. One White woman reported 'I've even tried to use my domestic worker's identity number to obtain tickets.' Some South Africans eventually just gave up trying to obtain tickets whilst others reacted with suspicion. This statement expresses it: 'I'm sure they have tickets that we don't know about.'

The researchers also identified the theme of flight in the responses of some of the participants. In discussing their own fears and those of their friends and family, some participants suggested that that the fear of 'being invaded' was so strong that it was leading to a number of physical flight reactions. Whilst some participants shared their intention of closing down their businesses for the duration of the 2010 FIFA World Cup or taking leave, others believed that it was an excellent opportunity to leave the country and enjoy a holiday abroad. It has also become common knowledge that flights out of South Africa were affordable during the event and it seemed that many South Africans would use the opportunity to escape the anxiety associated with the event.

Attempts to unite before the visitors arrived revealed a fifth theme of one-ness. The participants related many examples of South Africans of all races and ages attempting to create some cohesion and synergy before the 'outsiders' arrived. Many South Africans seemed to embrace the 2010 FIFA World Cup culture in the months leading up to the event and to adopt the rituals (songs and dances) associated with it. These South African rituals became commonplace at many different sports events and in the workplace and have had a unifying effect on South African society. This powerful union emerged in a number of ways that included displaying South African flags on cars, playing the vuvuzela and doing the South African diski dance that was developed specifically for the 2010 FIFA World Cup. 
In contrast to the theme of one-ness, a sixth theme of me-ness also seemed to emerge amongst some sections of the South African population. The participants reported that it is their view that, whilst some members of society were attempting to unite, others were trying to avoid the event by disconnecting from society. This is evident in statements like 'I'm not going out of my house' and 'I will watch it on television'.

\section{Discussion}

Although people often describe the effect of large-scale sports events in terms of the economic, infrastructure, sociocultural, psychological and sport dimensions, this research focused on the psychological experiences and effect of the 2010 FIFA World Cup on South African society. An analysis of the systems psychodynamic and positive psychology theoretical perspectives suggested that there might have been conflicting experiences in South Africa before the event. Whilst some members of the society may have expressed a great deal of hope that the event would have a positive effect on the psychological functioning of the society involved, others experienced unconscious fears and anxieties. This qualitative research was an explorative attempt to analyse some of the hopes and anxieties that prevailed in South African society before the 2010 FIFA World Cup. The findings that the researchers presented in a number of themes from the positive psychology seem to support the theoretical analysis.

The findings from the positive psychology perspective seem to reflect the hopes and dreams of many South Africans before the 2010 FIFA World Cup. The participants in this study presented them in relation to developing wisdom, knowledge and innovation as well as of developing effective relationships by hosting this important event in South Africa. Thematically, they also expressed the hope of spiritual development in South African society. This included the hope that the event would create pride and social intelligence in the society, together with opportunities for reconciliation and affiliation.

The participants also had long-term hopes for the country. They included a life of enjoyment and of engagement for all South Africans. Generally, the findings led the researchers to believe that a significant number of South Africans had an extremely positive view of the event and expected the event to have a far-reaching psychological effect on the spirit of the country. In the months leading up to the event, the nation seemed to develop a great deal of hope that the event would showcase the country at its best and show the role that the country could play as well as its potential contributions in the international arena. The country attempted to do this by showing its wisdom and knowledge, by acting as a beacon of hope for others and by providing a positive experience for the visitors. This, in turn, gave the nation a stronger identity and hope for the future.

On the eve of the event, the spiritual awakening of the nation seemed to create national pride and an acute awareness of socially intelligent behaviour. The development of pride, nation building, reconciliation and affiliation is most successful if the nation is able to balance a 'life of enjoyment' (engaging fully in the fun of the event) with the responsibilities of a 'life of engagement', which includes creating opportunities for others.

The findings from the systems psychodynamic perspective revealed equally valuable and unique insights. In contrast to the findings from the first perspective, in which the participants had similar positive experiences, the researchers analysed the anxieties and fears from this perspective. They showed a number of significant splits in South African society. There seemed to be a general fear about the effect of the visitors to South African soil. The persecutory anxiety seemed to be the result of South Africa's isolation from the rest of the world and the limited contact many South Africans have had with large groups of foreign visitors.

This anxiety seemed to lead to a number of splits between the visitors and the host nation. There were South Africans who were fully engaged in the event and those who were uninvolved or afraid to get too involved. There were supporters and non-supporters. There were younger and older South Africans. There were those who believed in the potential of the event to create pride and hope and there were sceptics.

In the months leading to the event, there seemed to be dependency and a depressive anxiety. This resulted from the conflicting expectations of the government and the organisers of the event. On the one hand, South Africans seemed to depend on the government and organisers to create a successful event and to improve the economy and lives of the members of the public. On the other hand, they seemed to de-authorise the leaders with concerns and fears of a perceived lack of competence and symbolic leadership.

In the months leading to the event, some members of the public seemed to react with competitiveness and fight reactions in an attempt to secure tickets for the event. Others reacted with flight and hopelessness because they believed that they would not be able to be part of the event and would not be able to secure tickets. This split the nation further into those who were engaged in the event and those who were unsupportive and detached. The latter group may even have responded with physical flight reactions, which included leaving the country or region for the duration of the event.

The arrival of large numbers of foreigners to the country at the same time seemed to have the effect of creating 'one-ness' in the local population who attempted to unite in a forceful way to cope with the perceived 'onslaught'. This unity emerged in symbolic ways with rituals, dances, gatherings and frequent interactions. They led people to surrender the self in passive participation and thereby felt existence, safety, well-being attachment and wholeness.

The isolation that South Africa experienced for many years seemed to create a lack of knowledge and understanding 
about interacting with foreign nationals. This resulted in a typical 'me-ness' culture, where there is little learning from history, authority figures or role models. The researchers observed this in some participants who tried to reduce their fear and psychic pain by withdrawing into a preoccupation with their own survival and by holding onto their own identities. This emerged in people who were not prepared to leave their homes unnecessarily during the event or even to leave the country for the duration of the event.

\section{Conclusion}

The researchers acknowledge that many South Africans seemed to feel more contained in the months before the event and received assurances about safety from the government, police and organisers. The researchers also emphasise the importance of conducting similar research after the 2010 FIFA World Cup in order to gain a better understanding of the dynamics and psychological processes involved in largescale sports events.

\section{Recommendations, limitations and suggestions for future research}

A general recommendation that seems to follow from this research is that governments should use effective change management programmes and effective communication strategies when planning and presenting large-scale sport events. This will give members of society the correct information and contain the anxiety that seems to accompany these events. The researchers also recommend that organisers conduct effective research on people's perceptions about these events so that the organisers can launch appropriate interventions before, during and after events to address the problems in the systems as well as the fears that may exist in the minds of the public. It seems more important and appropriate to conduct a later study of this nature to analyse the perceptions of South Africans after the event. Both participants and auditors suggested that the study is repeated to analyse the perceptions of the participants after the event.

An analysis of the differences may produce helpful insights into the dynamics that operate after an event of this magnitude. Although there is general agreement in the country that the event was a huge success, fears seemed to surface about its immediate and long-term financial implications as well as the disappointments that some members of the public may experience if the economic effect is not immediately visible. In general, the research provided rich in-depth information about psychological areas that researchers can explore and investigate further.

However, the study has some limitations about whether the findings are transferable. One of them is that the participants were all members of the economically active segment of South African society. Therefore, they are in a better position with regard to access to resources and finances.

\section{Acknowledgements Competing interests}

The authors declare that they have no financial or personal relationship(s) that may have inappropriately influenced them when they wrote this paper.

\section{Authors' contributions}

P.K. (University of Johannesburg) was the project leader. R.O. (University of South Africa) prepared and edited the manuscript academically.

\section{References}

Anderson, T.D., Rustad, A., \& Solberg, H.A. (2004). Local residents' monetary evaluation of sports events. Managing Leisure, 9, 145-158. http://dx.doi. org/10.1080/1360671042000273873

Arronga, W. (1975). More than a book review of Melanie Klein's psychoanalystic contribution. Journal of Contemporary Psychotherapy, 7(2), 130-133.

Babbie, E., \& Mouton, M. (2008). The practice of social research. (8th edn.). Cape Town: Oxford University Press.

Banet, A.G. Jr., \& Hayden, C. (1977). The Tavistock primer. In J.E. Jones \& J.W. Pfeiffer (Eds.). The 1977 annual handbook for group facilitators. San Diego, CA: University Associates.

Bertalanffy, Von, L. (1968). General systems theory. New York: Braziller.

Bion, W.R. (1961). Experiences in groups and other papers. New York: Basic Books. http://dx.doi.org/10.4324/9780203359075

Bion, W.R. (1974). Experiences in groups. New York: Basic Books.

Braun, V., \& Clarke, V. (2006). Using thematic analysis in psychology. Qualitative Research in Psychology, 3, 77-101. http://dx.doi.org/10.1191/1478088706qp063oa

Bryman, A., \& Bell, E. (2007). Business Research Methods. (2nd edn). New York: Oxford University Press.

Burnett, C. (2007). Siyadlala's contribution towards reaching the Millennium Development Goals. African Journal for Physical, Health Education, Recreation and Dance, Special Edition, 136-148.

Burnett, C. (2008, March). Assessing development of the 2010 Soccer World Cup. Paper presented at the University of Western Cape, Cape Town, South Africa.

Burnett, C., \& Hollander, W.J. (2007). The Sport-in-Development Impact Assessment Tool (S•DIAT). African Journal for Physical, Health Education, Recreation and Dance, Special Edition, 123-135.

Camic, PM., Rhodes, J.E., \& Yardley, L. (2003). Qualitative research in psychology. Washington: APA.

Chalip, L. (2006). Towards social leverage of sport events. Journal of Sport and Tourism 11(2), 109-127. http://dx.doi.org/10.1080/14775080601155126

Chandler, T. (1999). Making the Rugby World Cup, gender and commerce. London: Portland.

Cilliers, F., \& Koortzen, P. (2000). The psychodynamic view of organizational behaviour. The Industrial-Organizational Psychologist, 38(2), 59-67.

Clarkson, P., \& Nuttall, J. (2000). Working with countertransference. Psychodynamic Counselling, 6, 359-379. http://dx.doi.org/10.1080/13533330050132125

Compton, W.C. (2005). Introduction to positive psychology. Belmont, CA: Thomson Wadsworth.

Cornelissen, S., \& Swart, K. (2006). Sport mega-events: Social scientific analysis of a global phenomenon. In J. Horne \& W. Manzenreiter (Eds.). Oxford: Blackwell.

Cunningham, J., \& Beneforti, M. (2005). Investigating indicators for measuring the health and social impact of sport and recreation programmes in Australian
indigenous communities. International Review for the Sociology of Sport, 40(1), indigenous communities. International Review for the
89-98. http://dx.doi.org/10.1177/1012690205052170

Czander, W.M. (1993). The psychodynamics of work and organisations. New York: Guilford Press.

Czander, W.M. (1997). The psychodynamics of work and organizations: Theory and application. New York: Guilford Press.

Daniel, V. (2010). Object relations theory. Retrieved May, 19, 2010, from http://www. sonoma.edu/users/d/daniels/objectrelations.html

Doaldson, R., Cornelissen, S., Swart, K., \& Bob, U. (2008). Expectations of urban residents in the Western Cape on the 2010 FIFA World Cup. Africa Insight, 38(3), 35-48.

Gravetter, F.J. \& Forzano, L.B. (2012). Research Methods for the Behavioral Sciences. Wadsworth: Cengage Learning.

Higgs, P., \& Smith J. (2003). Rethinking truth. Lansdowne: Juta.

Jaques E. (1955). Social systems as a defence against persecutory and depressive anxiety. In M. Klein, P. Heimann \& R.E. Money-Kyrle (Eds.), New directions in psycho-analysis (pp. 478-498). London: Tavistock. 
Kerlinger, F.N., \& Lee, H.B. (2000). Foundations of behavioral research. Fort Worth: Harcourt College Publications.

Klein, M. (1985). Our adult world and its roots in infancy. In A.D. Colman \& M.H. Gelle (Eds.), Group relations reader 2 (pp. 5-19). Washington, DC: A.K. Rice Institute

Klein, J. (1987). Our adult world and its roots in infancy. London: Tavistock Institute.

Koortzen, P. \& Cilliers, F.V.N. (2002). The psychoanalytic approach to team development. In R.L. Lowman (Ed.). San Francisco: Jossey-Bass.

Labuschagne, P. (2008). The impact of sport on nation building: A critical analysis of South Africa and the 2010 FIFA World Cup. Africa Insight, 38(3), 3-14.

Laing, R.D. (1980). Self and others. New York: Penguin.

Lawrence, W.G. (1999). Exploring individual and organizational boundaries: A Tavistock open systems approach. London: Karnac.

Likierman, M. (2001). Melanie Klein: Her work in context. London: New York.

Lowman, R.L. (2002). The California School of Organizational Studies handbook of organizational consulting psychology: A comprehensive guide to theory, skills, and techniques. San Francisco: Jossey-Bass.

Mandela, N. (2008). Interview on the programme Springbok Saga, Super Sport. 26 June.

Marton, F. (1994). Phenomenography. In The International Encyclopaedia of Education Vol. 8 (pp. 4424-4429). Retrieved February 06, 2003, from http://www.ped.gu.se/ biorn/phgraph/civil/main/1res.appr.html

McCarthy, J.B. (1985). Resistance and primitive anxiety. Journal of American Academy of Psychoanalysis, 13, 181-189.
Miller, E.J. (1993). From dependency to autonomy: Studies in organization and change. London: Free Association Books.

Mouton, J. (1996). Understanding social research. Pretoria: Van Schaik.

Neumann, J.E. (1999). Systems psychodynamics in the service of political organizational change. In R. French \& R. Vince (Eds.), Group relations, management, and organization. (pp. 54-69). Oxford, UK: Oxford University Press.

Ohmann, S., Jones, I., \& Wilkes, K. (2006). The perceived social impact of the 2006 Soccer World Cup on Munich residents. Journal of Sport and Tourism, 11(2), 129152. http://dx.doi.org/10.1080/14775080601155167

Peterson, C., \& Seligman, M.E.P. (2004). Character strengths and virtues: A handbook and classification. Oxford, UK: Oxford University Press.

Ritchie, J.R.B. (1988). Assessing the impacts of the 1988 Olympic Winter Games: The research program and initial results. Journal of Travel Research, 22(3), 17-25.

Saayman, M., Saayman, A., \& Du Plessis, C. (2005). Analysis of spending patterns of visitors of three World Cup Cricket matches in Potchefstroom, South Africa. Journal of Sport Tourism, 10(3), 211-221. http://dx.doi.org/10.1080/14775080600611491

Segal, J. (1992). Melanie Klein. London: SAGE.

Seligman, M.E.P. (2002). Authentic happiness: Using the new positive psychology to realize your potential for lasting fulfillment. New York: Simon \& Schuster.

Seligman, M.E.P., \& Csikszentmihalyi, M. (2000). Positive psychology: An introduction. American Psychologist, 5, 5-14. http://dx.doi.org/10.1037/0003-066X.55.1.5, PMid:11392865

Schafer, R. (2003). Insight and interpretation: The essential tools of psychoanalysis. London: Karnac.

Turquet, P.M. (1974). Leadership: The individual and the group. In G.S. Gibbard, J. Harman \& R. Mann (Eds.), Analysis of groups (pp. 349-371). San Francisco: JosseyBass. 